\title{
Nikel Kaplanmış Alüminyum Levhaların Sürtünme Karıştırma Nokta Kaynağı ile Birleştirilebilirliğinin İncelenmesi
}

\author{
Investigation of Joinability of Nickel Coated Aluminum Sheets with Friction Stir Spot Welding
}

\author{
Murathan KALENDER $^{1}{ }^{(\mathbb{D}}$, Halil ULUPINAR ${ }^{1}$ (i) , Yahya BOZKURT $^{1}$ \\ ${ }^{I}$ Marmara Üniversitesi, Teknoloji Fakültesi, Metalurji ve Malzeme Mühendisliği, Istanbul, Türkiye
}

$\ddot{O} z$

Endüstride üretilen ürünlerin üzerinde çok çeşitli kaynaklı birleştirmeler yapılabilmektedir. Klasik ergitme kaynak yöntemlerinde oluşan sıcaklığa bağlı olarak kaynak bölgesinde gözenek, sıcak çatlak, yüksek 1sı girdisi nedeniyle çarpılma ve kimyasal element kaybı gibi problemler meydana gelmektedir. Sürtünme karıştırma nokta kaynağında bu hatalar elimine edildiğinden dolayı farklı malzemelerin birleştirme işlemlerinde sıklıkla kullanılmaktadır. Yöntem ile hem aynı cins hem de farklı malzeme kombinasyonlarında kaynak yapmak mümkündür. Sürtünme karıştırma nokta kaynăğ, birçok avantajı nedeniyle, otomotiv ve havacılık sektörleri dâhil olmak üzere çeşitli endüstrilerden büyük ilgi görmüş olan bir katı hal kaynak prosesidir. $\mathrm{Al}, \mathrm{Cu}, \mathrm{Mg}$ ve polietilen gibi malzemelerin kaynağı bu kaynak yöntemi ile sorunsuz bir şekilde yapılabilmektedir.

$\mathrm{Bu}$ çalışmada, nikel kaplanmış ve kaplanmamış AA2024-T3 levhalar sabit kaynak parametreleri kullanılarak sürtünme karıştırma nokta kaynak tekniği ile birleştirilmiştir. Elde edilen mekanik ve mikroyapısal deneyler sonucunda birleştirilen parçaların mekanik özellikleri değerlendirilmiştir.

Anahtar Kelimeler: Alüminyum, kaynak teknolojileri, nikel, sürtünme karıştırma nokta kaynağı.

\begin{abstract}
Various welded joints can be made on the products manufactured in the industry. Depending on the temperature formed in conventional melting welding methods, problems such as pore, hot crack, distortion and chemical element loss occur due to high heat input. Since these faults are eliminated in the friction stir spot welding, they are frequently used in the joining processes of different materials. With the method, it is possible to weld both the same type and different material combinations. Friction stir spot welding is a solid state welding process, which has attracted great attention from various industries, including the automotive and aerospace industries, due to its many advantages. Welding of materials such as $\mathrm{Al}, \mathrm{Cu}, \mathrm{Mg}$ and polyethylene can be made without any problem with this welding method.
\end{abstract}

In this study, nickel-coated and uncoated AA2024-T3 plates were combined with the friction stir spot welding technique using fixed welding parameters. The mechanical properties of the assembled parts were evaluated as a result of the obtained mechanical and microstructural experiments.

Keywords: Aluminium, welding technologies, nickel, friction stir spot welding.

\section{GİRIŞ}

Günümüz endüstrisinde en çok araştırma ve geliştirme çalışmaları, ağırlığı hafif ve mekanik özellikleri yüksek malzemeler üretmek üzerinedir. Otomotiv sektörü, hassas cihazların imalatı, uzay ve uçak teknolojileri, çelik yapılar, çelik eşya imalatı, boru üretimi, makine sektörü ve elektroteknik gibi pek çok alanda kullanılan metal malzemelerin kaynağında yaşanan sorunlar, farklı kaynak türlerinin gelişimini sağlamıştır. Ayrıca, bu sektörlerde kullanılacak malzemelerde istenilen hafiflik ve yüksek dayanım özelliği, sandviç (en az 3 katmanlı) malzemelerin geliştirilmesini sağlamıştır. Her katmanda farklı çeşitlerde kullanılan malzemeler hem hafiflik hem de kaynaklanabilirlik açısından olumlu sonuçlar vermektedir. Geliştirilen bu malzemelerin ve yapıların birleştirilmesinde katı hal kaynak yöntemleri daha etkili olmuştur. Katı hal kaynak yöntemlerinden biri olan sürtünme karıştırma kaynağından türeyen sürtünme karıştırma nokta kaynak (SKNK) yöntemidir. Elektrik direnç nokta kaynağına (EDNK) alternatif olarak geliştirilen ve sürtünme karıştırma kaynağı yöntemi temel alınarak geliştirilen SKNK yöntemi, kaynak teknolojisi konusunda karşımıza çıkan en son gelişmelerden birisidir. Yöntem, nokta sürtünme kaynağı veya sürtünme nokta birleştirmesi olarak da adlandırılmaktadır [1].

SKNK düşük maliyetli ve yüksek performans göstermesini isteyen bağlantılar için ideal bir yöntemdir. SKNK ile 
çelik, alüminyum, bakır, nikel, titanyum, polietilen vb. malzemelerin birleştirilmesi yapılabilmektedir. Metalik malzemeler ergitilmeden, malzemelerin ergime sıcaklıklarının altında bir sıcaklıkta malzeme katı haldeyken kaynak işlemi gerçekleştirilmektedir [2].
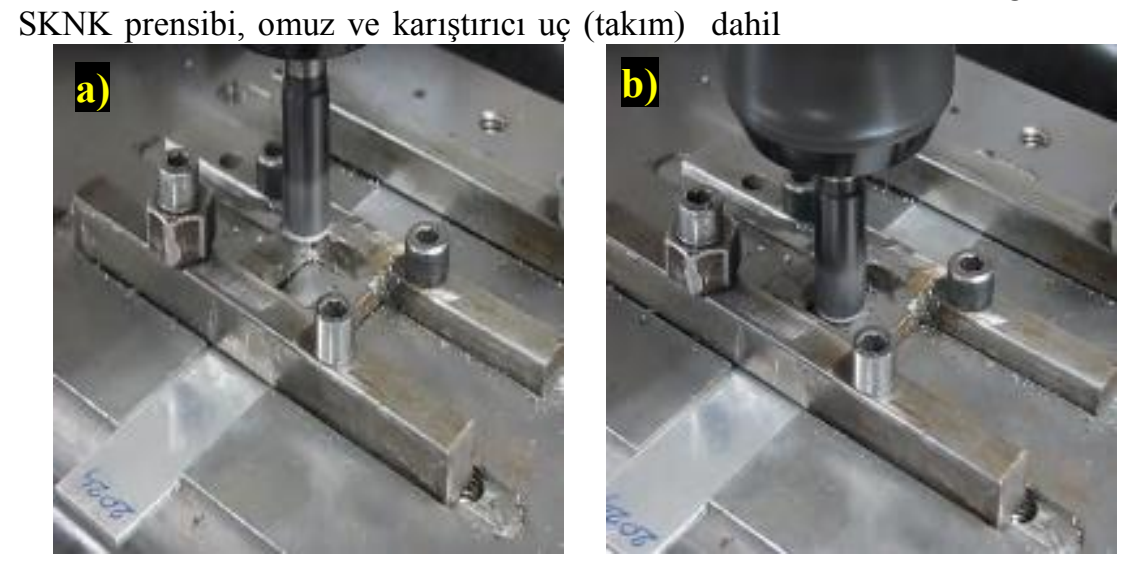

olmak üzere iki parçadan oluşan ergimeyen bir karıştırıcı yardımıyla takımın parça üzerinde nokta birleştirme işlemi yapmasıdır. SKNK işlemi, farklı hızlara sahip dönen takımın levhalar arasına daldırılması, 1Sı ve basınç yardımıyla nokta kaynak işleminin gerçekleştirilmesidir. Şekil 1'de SKNK işlem basamakları gösterilmektedir [3].
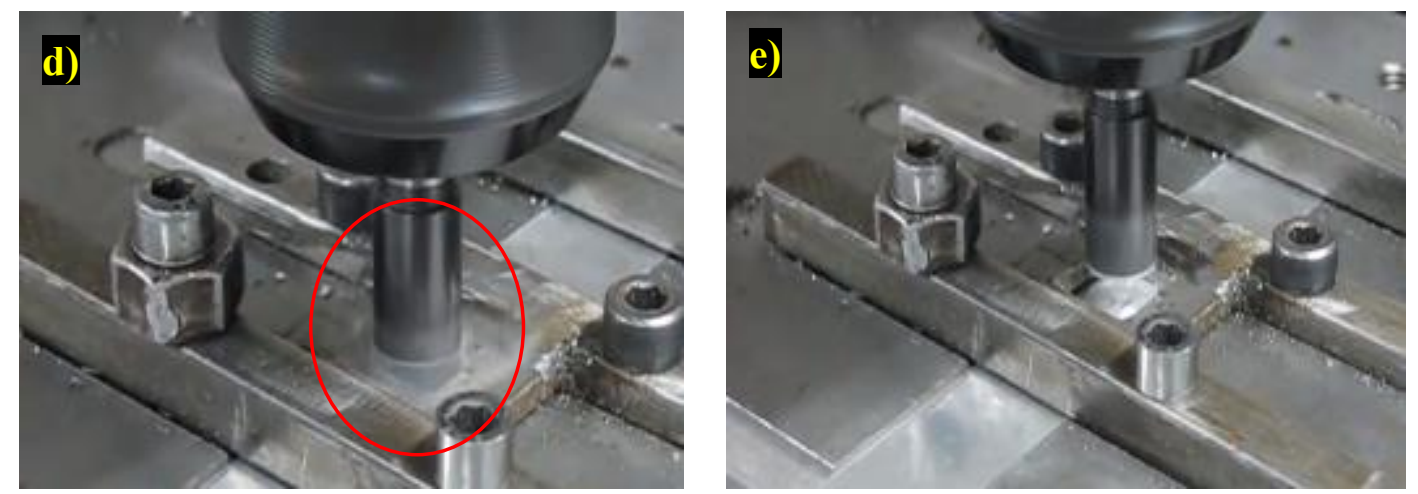

Şekil 1. SKNK basamakları; a) SKNK öncesi, b) SKNK öncesi temas halindeki karıştırıcı uç, c) Omuzun malzeme yüzeyine temasla ısı oluşturması, d) Katı hal birleşme, e) İşlemin sonlanması ve kaynak takımının geri çekilmesi [3]

Al-Fe gibi benzer olmayan iki metalin klasik nokta kaynak yöntemleriyle birleştirilmesi mümkün olmamaktadır. Al, Sn, Zn, Zn-Pb alaşımlı kaplanmış çeliklerin EDNK ile birleştirilmesinde özel kaynak ekipmanlarına ihtiyaç duyulmaktadır. SKNK yönteminin büyük benzerlikler gösterdiği EDNK' dan daha az teçhizat maliyeti ve çok düşük enerji tüketimi gerektiği için ekonomik avantaj sağlamaktadır [4].

SKNK'nın diğer geleneksel kaynak yöntemlerine göre avantajlarını metalurjik, çevresel ve enerji olmak üzere üç ana grupta inceleyebiliriz. SKNK yöntemi katı fazda gerçekleştiğinden dolayı kaynak bölgesindeki malzemeye metalurjik olarak hasar vermez. Fakat, bazı alaşımların ergitmeli birleştirilmelerinde kalitesinde büyük sorunlar meydana gelmektedir. Klasik ergitme kaynak yöntemlerinde oluşan sıcaklığa bağlı olarak kaynak bölgesinde gözenek, sıcak çatlak, yüksek 1S1 girdisi nedeniyle çarpılma ve kimyasal element kaybı gibi problemler meydana gelmektedir [5].
İşlem sırasında sıcaklığın diğer kaynak yöntemlerine göre daha az olması, iş parçasındaki burulmaları en aza indirgemektedir. Bu yöntem, iyi bir boyutsal kararlılık ve tekrar edilebilme özelliğine sahip olmasının yanı sıra alaşım elementleri üzerinde kayıplar oluşmamaktadır. SKNK sonrasında birleşim bölgesi ince taneli mikroyapıya sahip olduğundan bu bölge mükemmel metalurjik özelliklere sahiptir. Isı girdisi nedeniyle iş parçasında çatlak oluşmaz. Çevresel ve enerji avantajlarına bakıldığında; gaz altı kaynaklarındaki gibi koruyucu gaza gerek yoktur. Ayrıca alüminyum sacların EDNK işleminde bazı büyük problemler meydana gelmektedir. $\mathrm{Bu}$ problemlerin başında; çatlamalar, porozite, sıçramalar ve kaynak elektrot aşınması gelmektedir [6-7]. SKNK işlemi sonrasında sıçrama olmadığından yüzey temizliğine gerek kalmaz ve taşlama atıkları oluşmaz. SKNK yöntemiyle gelişmiş malzemelerde birleştirme yapılırken bu malzemelerin hafif olmasında büyük rol alır. Şekil 2'de sandviç levhaların SKNK ile kaynak işleminin şematik hali görülmektedir. 

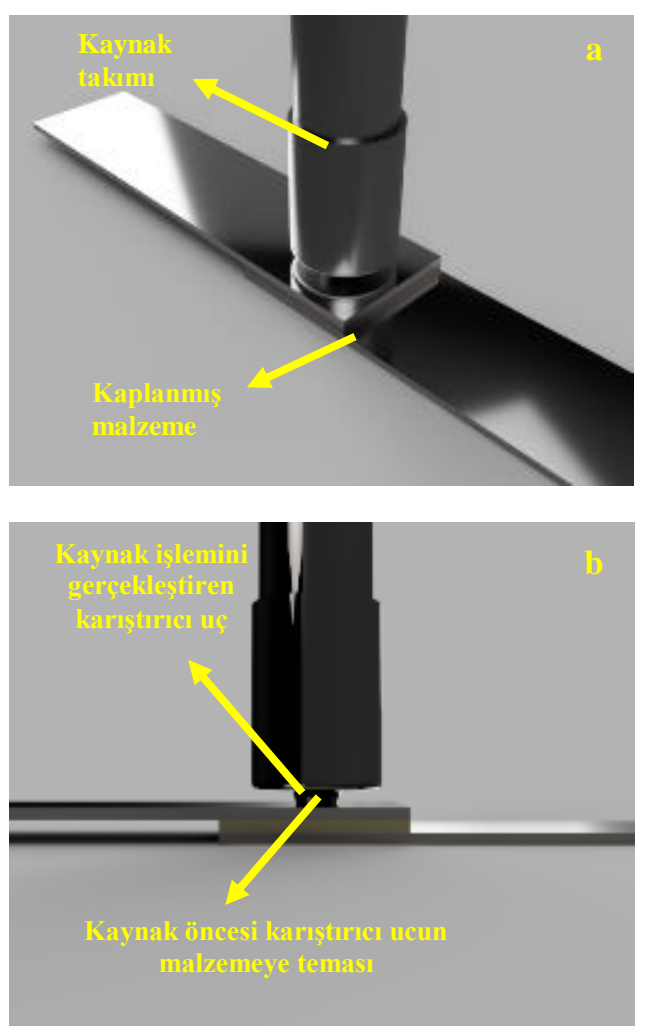

Şekil 2. SKNK işleminde 3 boyutlu şematik görünümü, a) İzometrik görünüş, b) Önden görünüş

SKNK yöntemi homojen bir sıcaklık dağılımı sağlamaktadır. Takımın omuz ve karıştırıcı ucunun aşınması ve kırılması, takım malzemesinin seçimi için ciddi bir sınırlama getirmektedir. SKNK sonucunda, takımlar işlem sırasında ulaşılan sıcaklıklarda yüksek mekanik dirence sahip olmalıdır. Bununla beraber aşınma ve oksitlenmeye karşı direnç sağlayabilmelidir. SKNK işlemlerinde sıcaklığın tipik olarak işlenmiş malzeme için, ergime sıaklığının yaklaşık \% 80 oranına ulaştığı gözlemlenmiştir [8]. Bununla birlikte, ana metalde oluşan sıcaklıkla birlikte takım içindeki sıcaklık önemli bir değişkendir.

Takım omzu sürtünme veya deformasyon 1sısının büyük bir kısmını oluşturur; karıştırıcı uç iş parçaları arasındaki malzeme akışına yardımcı olur. Takımın profili ve geometrisinin yanı sira SKNK'da yer alan diğer parametreler; takım dönme hızı, dalma (daldırma) derinliği ve bekleme süresidir. Bu proses parametreleri kaynaklı birleştirmenin dayanımını ve yüzey kalitesini belirler. SKNK'dan sonra karışım bölgesinde farklı mikroyapısal bölgeler görülür. Şekil 3' de SKNK işleminde kullanılan takımın örnek geometrisi ve batma derinliği şematik olarak gösterilmiştir.

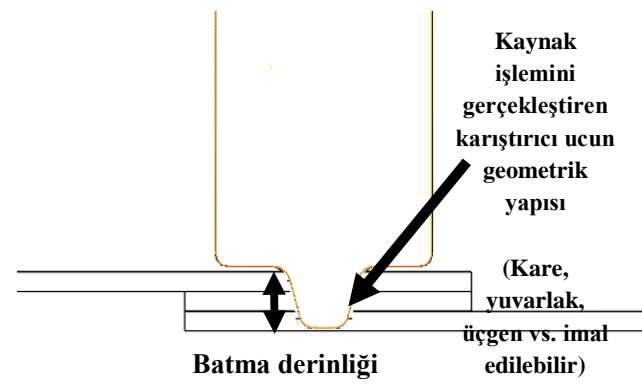

Şekil 3. SKNK işleminde kullanılan takımın örnek bir geometrisi ve batma derinliğinin şematik olarak gösterimi

Kullanımı zamanla artan SKNK yönteminin uygulama alanları da gün geçtikçe artmaktadır. SKNK yönteminin ihtiyaçlara cevap verebilecek şekilde gelişmesini sağlayabilmek için de kaynak sırasında kullanılan alet, donanım ve makinelerinde geliştirilmesi gerekmektedir [9]. Kaynak işleminde kullanılan fikstür, takım ve karıştırıcı uç geometrisinin, kaynak kalitesine ve mekanik özelliklerine doğrudan etki ettiği daha önceki çalışmalarda görülmüştür [1011]. SKNK uygulamalarında kaynak edilecek malzemenin cinsine bağlı olarak yüksek sıcaklıklarda aşınma direncine sahip takımlar kullanılmaktadır. Önceki çalışmalarda Al ve Al alaşımları için kullanıldığında alaşımsız çeliklerden yapılmış takımlar ile iyi sonuçlar alınmıştır. Ancak 1sıl işlem görmüş bazı Al türlerinde kullanıldığında takımın aşınmasına ve kısa sürede kırılmasına neden olmuştur. Zaman içinde alaşımsız çelik takımlar yerini alaşımlı çelik takımlara bırakmıştır [12]. SKNK prosesinde kullanılan takımlar, takım omuz ve karıştırıcı uç geometrisine göre farklı yapılarda olabilmektedirler [13]. SKNK yönteminde kullanılan bazı takım omuz yapıları Şekil 4'te gösterilmektedir.
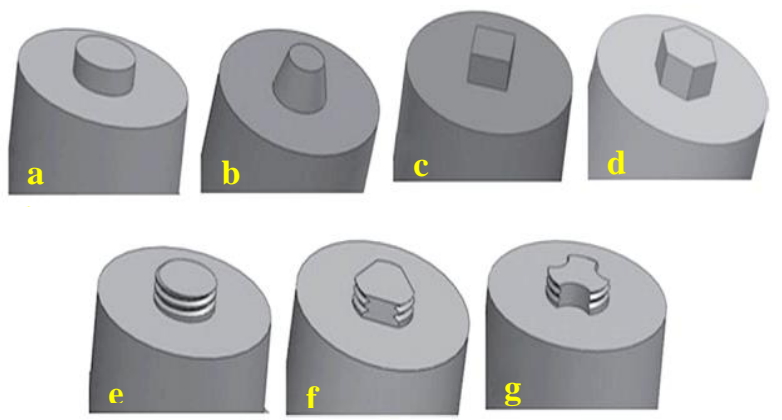

Şekil 4. Farklı karıştırıcı uç geometrileri: (a) silindirik,

(b) konik silindirik, (c) kare, (d) altıgen, (e) dişli silindirik, (f) dişli üçgen, and (g) dişli üç köşeli yıldız [13] 
Son yıllarda otomotiv sektöründe genellikle kullanılan çelik sacların yerine daha hafif alaşımların kullanılması yönünde önemli kararlar alınmaktadır. Otomobil gövde yapımında ve kapalı panellerde; bagaj kapağı, motor kapağı gibi arabanın birçok bölgesinde alüminyum alaşımı saclar ya da daha ince kesitlerde yüksek mukavemetli çelik saclar kullanılarak gövde ağırlığı azaltılmıştır. Ağırlığın azaltılması otomotiv endüstrisinde önemli yakıt tasarrufları sağlamaktadır [14]. Yöntemin olumlu özellikleri dikkate alındığında SKNK yönteminin endüstride uygulama alanı bulması oldukça kolay bir hale gelmiştir. SKNK tekniğinin yaygın kullanım alanları Tablo 1'de gösterilmiştir.

Tablo 1. SKNK tekniğinin yaygın kullanım alanları [15-17]

\begin{tabular}{|c|c|}
\hline $\begin{array}{c}\text { Endüstri } \\
\text { Alanı }\end{array}$ & Uygulama Alanı \\
\hline $\begin{array}{l}\text { Denizcilik } \\
\text { Endüstrisi }\end{array}$ & $\begin{array}{l}\text { Güverte için paneller, yan yüzler, bölme ve } \\
\text { zeminlerde, alüminyum ekstrüzyonlarında, gemi } \\
\text { bölmelerinde, gemi omurga ve üst yapılarında, } \\
\text { helikopter merdiven platformlarında, } \\
\text { kamaralarda, denizcilik yapılarında, yelkenli } \\
\text { gemi için; gemi direk ve zincirlerinde, soğutma } \\
\text { tesislerinde, gemi iskeletleri, güverteler ve } \\
\text { yüksek hızda gemiler için enerji verimliliği ve } \\
\text { hafiflik için iç tasarımlarda uygulanmaktadır. }\end{array}$ \\
\hline $\begin{array}{l}\text { Havacılık } \\
\text { Endüstrisi }\end{array}$ & $\begin{array}{l}\text { Kanatlar, uçak gövdesi ve kuyruk kısımlarında, } \\
\text { uzay araçları için kriyojenik yakıt tanklarında, } \\
\text { havacılık yakıt tanklarında, askeri uçaklar için dış } \\
\text { atık tanklarında, askeri ve araştırma roketlerinde, } \\
\text { hatalı MIG kaynaklarının düzeltilmesinde ve öze } \\
\text { alaşımlı yüzeylerin bağlantı kısımlarında } \\
\text { kullanılmaktadır. }\end{array}$ \\
\hline $\begin{array}{l}\text { Demiryolu } \\
\text { Endüstrisi }\end{array}$ & $\begin{array}{l}\text { Yüksek hızda trenlerin imalinde, demiryolu } \\
\text { araçları, yeraltı taşımacılığı ve tramvaylarda, } \\
\text { demiryolu tankları ve yük vagonlarında, } \\
\text { konteyner iskeletlerinde, vagon ve vagon şasisi } \\
\text { ile yüksek hızda trenler için karoserlerde } \\
\text { uygulanmaktadır. }\end{array}$ \\
\hline
\end{tabular}

\begin{tabular}{|c|c|}
\hline $\begin{array}{c}\text { Kara } \\
\text { Taşımacılığı }\end{array}$ & $\begin{array}{l}\text { Motor ve şasi yataklarında, tekerlek jantı } \\
\text { imalinde, uygun hale getirilmiş boşluklar v.b. } \\
\text { farklı levha kalınlıklarının kaynağında, kamyon } \\
\text { iskeletlerinde, kamyonetlerin } \\
\text { kaldıraçlarında, hareketli vinç imalinde, } \\
\text { kaportası zırhlı araç imalinde, yakıt tanklarında, } \\
\text { karavanlarda, otobüs taşımacılığında, motosiklet } \\
\text { ve bisiklet gövdelerinde, asansörlerde, Al } \\
\text { otomobillerin tamirinde, ayrıca alüminyum esaslı } \\
\text { arabalarda iç panellerinin üretiminde } \\
\text { uygulanmaktadır. }\end{array}$ \\
\hline $\begin{array}{l}\text { Yap1-inşa } \\
\text { Endüstrisi }\end{array}$ & $\begin{array}{l}\text { Alüminyum köprüler, } \mathrm{Al}, \mathrm{Cu} \text { ya da } \mathrm{Ti} \text { ' den } \\
\text { yapılmış binanın ön yüz panellerinde, pencere } \\
\text { iskeletlerinde, alüminyum boru hatlarında, enerji } \\
\text { santralı ve kimya endüstrisi için } \mathrm{Al} \text { reaktörlerde, } \\
\text { isı değiştirici ve klimalarda, boru üretiminde } \\
\text { uygulanabilmektedir. }\end{array}$ \\
\hline $\begin{array}{c}\text { Elektrik } \\
\text { Endüstrisi }\end{array}$ & $\begin{array}{l}\text { Elektrikli motor çerçevesinde, elektrik bağlama } \\
\text { çubuklarında, elektriksel bağlantılarda, } \\
\text { elektronik sargılarda kullanılmaktadır. }\end{array}$ \\
\hline $\begin{array}{l}\text { Diğer } \\
\text { Endüstri } \\
\text { Sektörleri }\end{array}$ & $\begin{array}{l}\text { Soğutma panelleri, aşçılık ekipmanları ve } \\
\text { mutfaklarda, beyaz eşyalarda, gaz tankları ve gaz } \\
\text { silindirlerinde, un değirmenlerindeki bakır ya da } \\
\text { alüminyum bobin bağlantılarındaki } \\
\text { uygulamalarda kullanılmaktadır. }\end{array}$ \\
\hline
\end{tabular}

\section{DENEYSEL ÇALIŞMALAR}

\subsection{Malzemeler}

Yapılan çalışmada, SKNK işlemi için 1,6 mm kalınlığında kaplanmamış AA2024-T3 alüminyum alaşımı levha ve Ni kaplı AA2024-T3 alüminyum alaşımı levha kullanılmıştır. AA2024-T3 alüminyum ve Ni alaşımının ve kimyasal bileşimi Tablo 2 ve Tablo 3 'te gösterilmiştir. Alüminyum levhalar $25 \times 100 \mathrm{~mm}$ boyutlarında ve Ni levhalar $25 \times 25 \mathrm{~mm}$ boylarında kesilmiştir. Levha üzerine uygulanan kaynak bölgesi $25 \times 25 \mathrm{~mm}$ olarak belirlenmiştir. SKNK işlemi yapılan freze makinasında SKNK esnası Şekil 5'te gösterilmiştir.

Tablo 2. AA2024-T3 alüminyum alaşımının mekanik ve kimyasal özellikleri [18]

\begin{tabular}{|c|c|c|c|c|c|c|c|c|c|c|c|}
\hline \multirow{2}{*}{ Malzeme } & \multicolumn{2}{|c|}{$\begin{array}{c}\text { Mekanik } \\
\text { Özellikler }\end{array}$} & \multicolumn{7}{|c|}{ Kimyasal Bileşim (Ağırlıça \%) } \\
\cline { 2 - 11 } & $\begin{array}{c}\text { Çekme } \\
\text { Dayanımı } \\
\text { (MPa) }\end{array}$ & $\begin{array}{c}\text { Uzam } \\
\mathbf{a}(\%)\end{array}$ & Al & Si & Fe & Cu & Mn & Mg & Zn & Ti & Cr \\
\hline AA2024-T3 & 435 & 17 & 93.11 & 0.07 & 0.14 & 4.5 & 0.65 & 1.5 & 0.01 & 0.02 & - \\
\hline
\end{tabular}


Tablo 3. Nikel alaşımının kimyasal kompozisyonu [18]

\begin{tabular}{|c|c|c|c|c|c|c|}
\hline \multirow{2}{*}{ Malzeme } & \multicolumn{6}{|c|}{ Kimyasal Bileşim (Ağırlıça \%) } \\
\cline { 2 - 7 } & $\mathbf{N i}$ & $\mathbf{F e}$ & $\mathbf{C u}$ & $\mathbf{S}$ & $\mathbf{O}$ & Co \\
\hline $\mathrm{Ni}$ & 29,23 & 34,58 & 10,84 & 19,05 & 4,56 & 0,48 \\
\hline
\end{tabular}
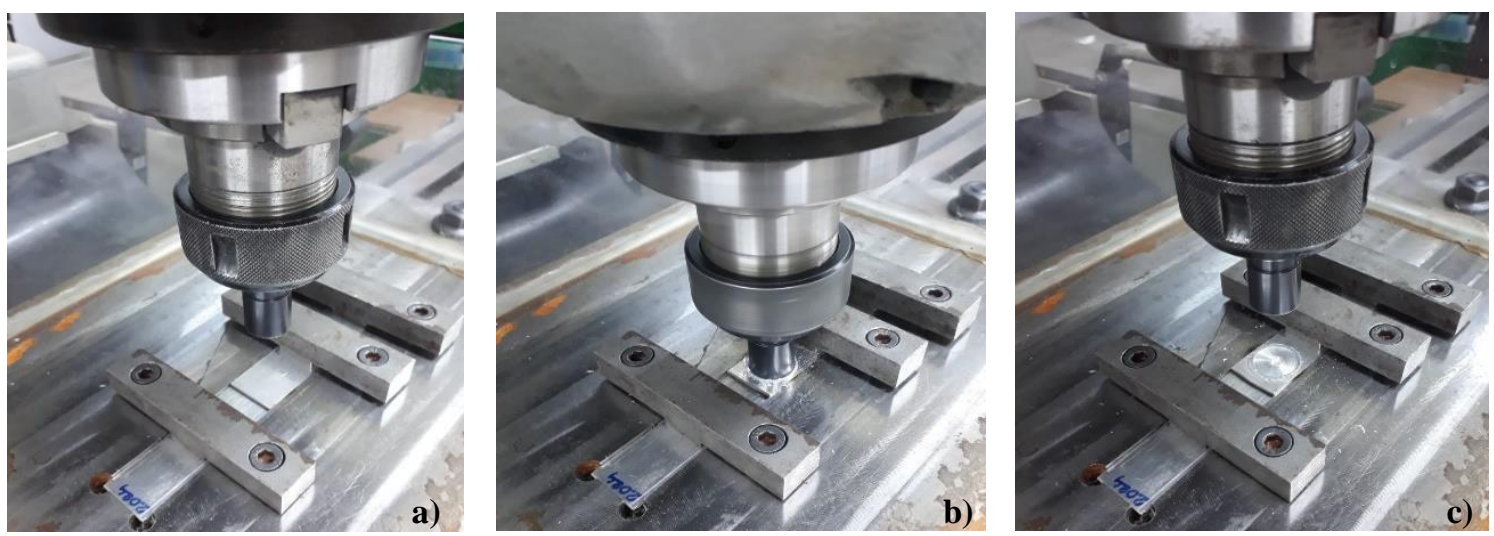

Şekil 5. a) SKNK işlemi öncesi parçaların fikstüre sabitlenmesi, b) SKNK uygulaması, c) SKNK sonrası birleşen numuneler

\subsection{SKNK İşlemi ve Kaynak Parametreleri}

SKNK işleminde Alüminyum Titanyum Nitrat (AlTiN) kaplı takım kullanılmıştır. Bu takım 1.2344 kalite sıcak iş takım çeliğinden imal edilmiştir. SKNK takımının omuz çap1 $18 \mathrm{~mm}$, karıştırıcı uç çapı $6 \mathrm{~mm}$ olarak imal edilmiştir. Kullanılan takım ve ölçüleri Şekil 6'da gösterilmiştir. Birleştirme işlemi, takımın saat yönünde döndürülmesiyle gerçekleştirilmiş olup kaynak işlemi oda sıcaklığında gerçekleştirilmiştir. SKNK işleminde takım dönme hızı 1040 dev/dak. olarak sabitlenmiştir. Takımın kaynak bölgesindeki süresi 10 s olarak belirlenmiştir.
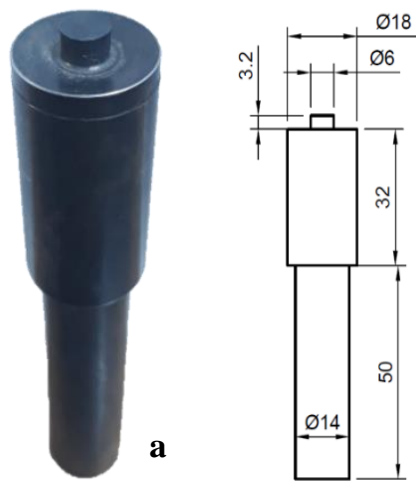

b

Şekil 6. a) SKNK işleminde kullanılan takım, b)

SKNK işleminde kullanılan takımın ölçüleri

\section{3. Çekme Makaslama Deneyi}

Birleştirilmiş AA2024-T3/Ni/AA2024-T3 ve AA2024T3/AA2024-T3 deney numuneleri ASTM-D638 standartına göre test edilmiştir. Çekme deneyi Zwick Z010 model çekme test cihazında gerçekleştirilmiş olup Şekil 7' de gösterilmiştir. Çekme testi oda sıcaklığında ve $5 \mathrm{~mm} / \mathrm{s}^{\prime}$ lik sabit çekme hızında gerçekleştirilmiştir. Her parametre için çekme- makaslama testi sonucu alınıp ortalamalar belirlenmiştir. Çekme testi uygulanmış numuneler Şekil 8'de gösterilmiştir.
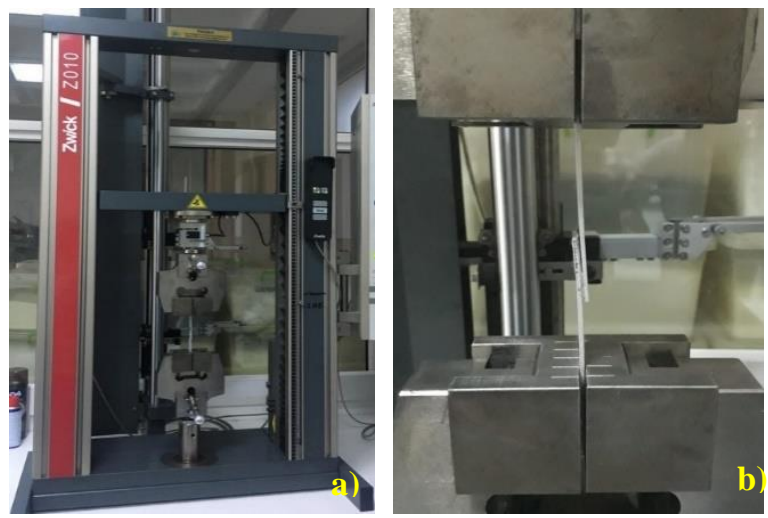

Şekil 7. a) Zwick Z010 model çekme test cihazı,

b) Makine çenesine bağlanmış test numunesi
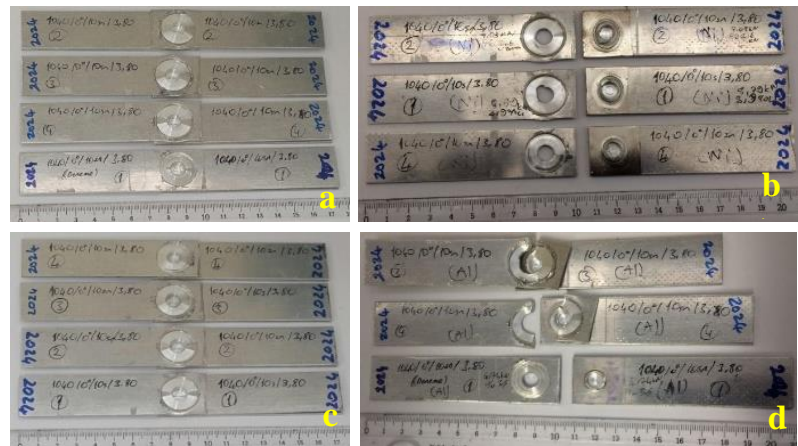

Şekil 8. a) Test öncesi AA2024/Ni/AA2024

numuneler, b) Test sonras1 AA2024/Ni/AA2024

numuneler, c) Test öncesi AA2024/AA2024

numuneler, d) Test sonras1 AA2024/AA2024 numuneler 


\subsection{Mikroyapı}

Hazırlanan kaynak numunelerinin kaynak bölgesi üzerinden Buehler Abrasimet 2 cihazı ile uygun kesitte parçalar kesilmiştir. Kesilen parçalara bakalitleme işleminden sonra metalografik işlemler uygulanmıştır. Dağlama reaktifi olarak Keller reaktifi kullanılmıştır. Mikroyap1 görüntüleri Olympus BX61M model mikroskop cihazından alınmıştır. Metalografik işlemlerde kullanılan numune kesim cihazı ve mikroskop cihazı Şekil 9'da gösterilmiştir.
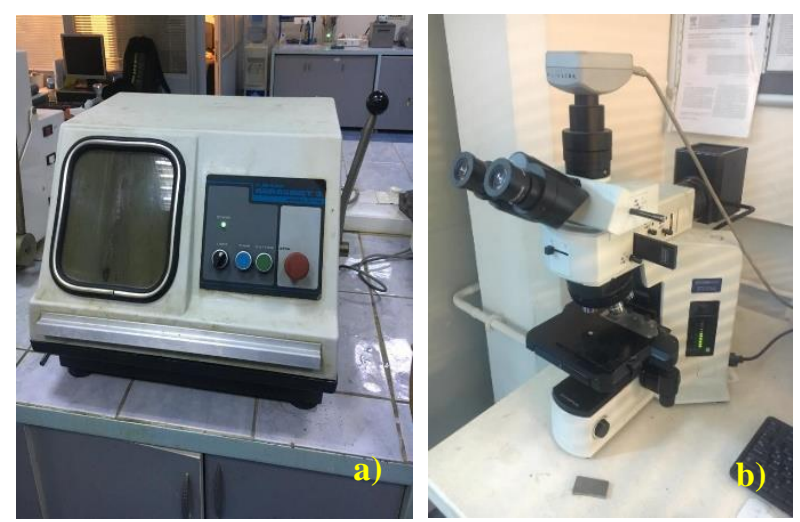

Şekil 9. a) Numune kesme işlemi yapılan Buehler Abrasimet 2 cihazı, b) Mikroyapı görüntüleri alınan Olympus BX61M model mikroskop cihazı

\subsection{Mikrosertlik}

Mikrosertlik deneyleri için, Şekil 10a' daki FM-310e marka mikrosertlik cihazı kullanılmıştır. Şekil 10b'de gösterildiği gibi SKNK kesitinden kesilen numunelerden, alt ve üst bölgelerden $\mathrm{x}$ hattı boyunca her iki yönde olmak üzere 1'er mm aralıklarla ölçüm alınmıştır. Mikrosertlik ölçümleri 10 s'lik bir süre ve 200 gr yük parametrelerinde alınmıştır.

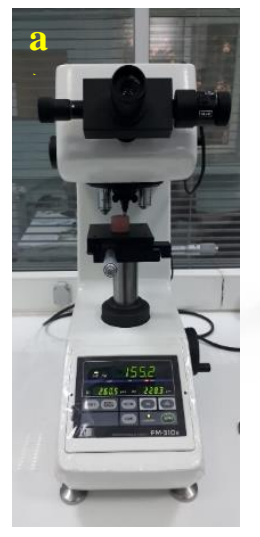

b
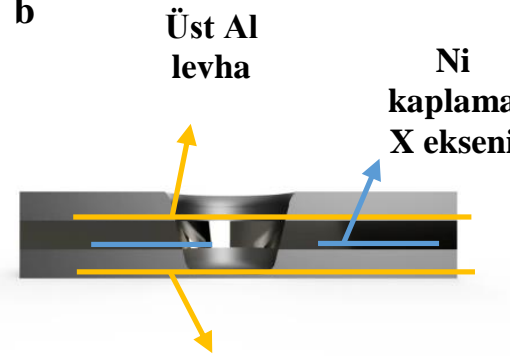

\section{Alt Al levha \\ $\mathrm{X}$ ekseni}

Şekil 10. a) Kullanılan FM-310e marka mikrosertlik cihazı, b) Numune üzerinde sertlik alınan x ekseni bölgeleri

\section{SONUÇLAR VE TARTIŞMA}

\section{1. Çekme Makaslama Deneyi Sonuçları}

SKNK işlemi sonucu yapılan çekme-makaslama testlerine bakıldığında optimum çekme kuvvetinin karıştırıcı ucun $2.8 \mathrm{~mm}$ derinliğe kadar daldırıldığ numunelerde olduğu görülmektedir. Dalma derinliği 2.8 mm'nin daha üstündeki bir değer ile birleştirilen numunelerde mukavemet değerlerinin azaldı $\breve{g}_{1}$ görülmüştür. Bunun nedeni birleştirilen bölgenin altında kalan metal kalınlığının incelmesidir. Çekmemakaslama kuvvetini etkileyen diğer faktörlerden biri de kullanılan karıştırıcı ucun uzunluğu ve profilidir. Karıştırıcı ucun profili birleştirilen bölgedeki malzeme akışını doğrudan etkilemektedir. SKNK işlemi sırasındaki karıştırıcı uç uzunluğu ve dalma derinliği de malzeme akışını etkileyecektir. Ayrıca bu parametreler 1S1 oluşumunu etkileyerek kaynak dayanımını belirlemektedir [19]. SKNK yöntemi ile birleştirilen numunelerin çekme makaslama deneyi sonuçları Tablo 4'te gösterilmiştir. Sonuçlar, Şekil 11 ve Şekil 12'de grafik olarak verilmiştir. Numunelerin çekmemakaslama kuvveti ve \% uzama değerleri belirlenmiştir. Ara malzeme ilavesiz (kaplama olmadan) birleştirilen numunenin ortalama çekmemakaslama kuvveti $6,78 \mathrm{kN}$ ve \% uzama değeri \% 3,56 olarak görülmüştür. Ni kaplanmış numunenin ortalama çekme-makaslama kuvveti 7,91 kN ve \% uzama değeri \%3,23 olarak belirlenmiştir. Karıştırıcı ucun etki ettiği gerilim sonucunda 1sı ve karıştırma etkisinde kalan bölgeye doğru gidildikçe sertlikte artış elde edilmiştir. $\mathrm{Bu}$ sertlik artışının alüminyum ve kaplama ile etkileşiminden ve dinamik yeniden kristalleşmeyle oluşan ince taneli yapıdan kaynaklandığı düşünülmektedir [20]. Ayrıca Al-Ni sisteminde kararlı yapılar, en yüksek ergime noktasına, oldukça düşük yoğunluğa, iyi mukavemet özelliklerine ve yüksek sicaklıklarda korozyon ve oksidasyon direncine sahiptirler [21].

Tablo 4. Çekme makaslama deneyi sonuçları

\begin{tabular}{|c|c|c|c|c|}
\hline \multirow{2}{*}{$\begin{array}{c}\text { Deney } \\
\text { No }\end{array}$} & $\begin{array}{c}\text { AA2024- } \\
\text { T3/AA20 } \\
\mathbf{2 4 - T 3}\end{array}$ & $\begin{array}{c}\text { AA2024- } \\
\text { T3/Ni/AA2 } \\
\text { 024-T3 }\end{array}$ & $\begin{array}{c}\text { AA2024- } \\
\text { T3/AA20 } \\
\mathbf{2 4 - T 3}\end{array}$ & $\begin{array}{c}\text { AA2024- } \\
\text { T3/Ni/AA2 } \\
\text { 024-T3 }\end{array}$ \\
\cline { 2 - 5 } & \multicolumn{2}{|c|}{$\begin{array}{c}\text { Cekme-makaslama } \\
\text { kuvveti (kN) }\end{array}$} & \multicolumn{2}{|c|}{ Uzama (\%) } \\
\hline 1 & 8.31 & 8.79 & 3.7 & 3.9 \\
\hline 2 & 7.30 & 7.91 & 3.5 & 3.2 \\
\hline 3 & 4.74 & 7.03 & 3.5 & 2.6 \\
\hline $\begin{array}{c}\text { Ortala } \\
\text { ma }\end{array}$ & $\mathbf{6 . 7 8}$ & $\mathbf{7 . 9 1}$ & $\mathbf{3 . 5 6}$ & $\mathbf{3 . 2 3}$ \\
\hline
\end{tabular}

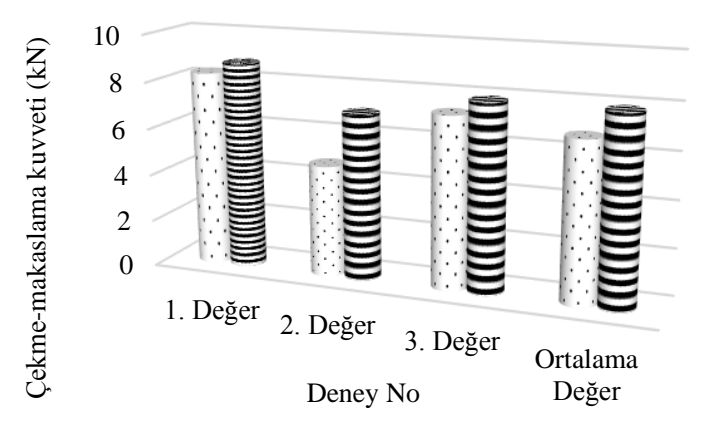

AA2024-T3/AA2024-T3 = AA2024-T3/Ni/AA2024-T3

Şekil 11. AA2024-T3/AA2024-T3 ve AA2024T3/Ni/AA2024-T3 çifti için çekme makaslama deneyi yük değerleri 


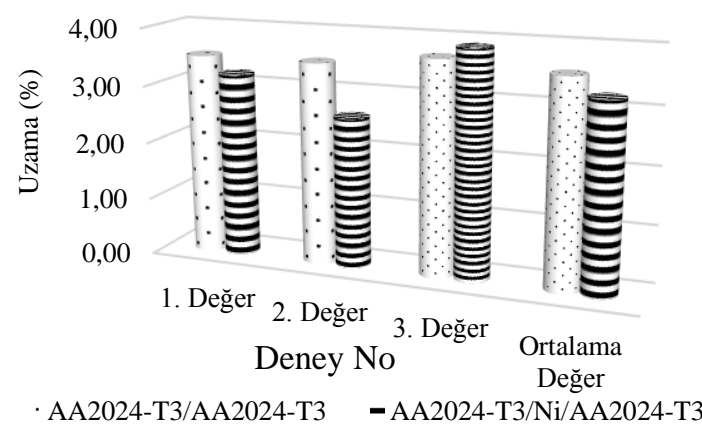

Şekil 12. AA2024-T3/AA2024-T3 ve AA2024T3/Ni/AA2024-T3 çifti için uzama değerleri

\subsection{Mikroyapı Sonuçları}

Birleştirmenin merkezinde bulunan kaynak bölgesinin boyutu, kullanılan kaynak takımının geometrisine bağlı olarak değişmektedir. SKNK ile birleştirilmiş parçalarda, karışım bölgesi (KB), termo-mekanik olarak etkilenen bölge (TMEB), 1sı tesiri altında kalan bölge (ITAB) ve ana metal bölgesi olarak toplamda dört bölge bulunmaktadır. Şekil 13'te görüldüğü I. bölge ITAB'1, II. bölge TMEB'i ve III. bölge KB' yi göstermektedir. Bu farklı bölgelerdeki mikro yapı değişimleri kaynak sonrası mekanik özelliklere önemli etkiler yapmaktadır.
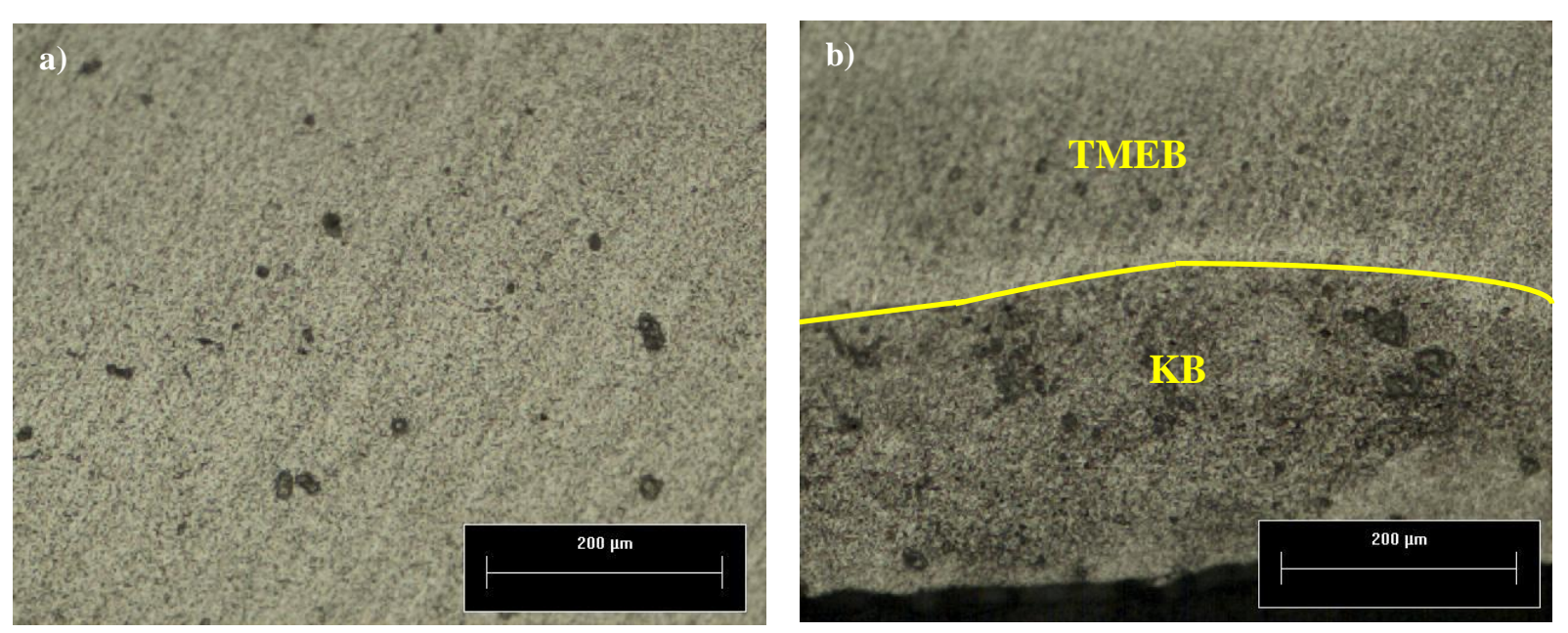

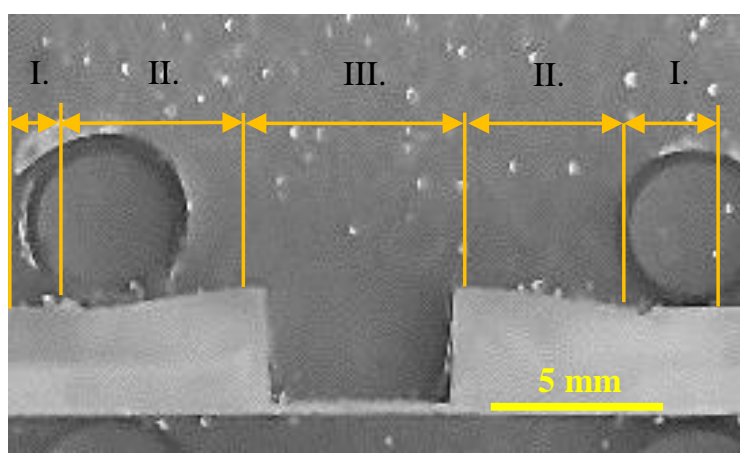

Şekil 13. SKNK ile birleştirilmiş parçalarda oluşan bölgeler

TMEB'de sıcaklık kaynak bölgesine göre daha düşük olduğundan burada gerilme düşüktür fakat deformasyon yüksektir. ITAB, kaynak esnasında termal bir çevrime maruz kalmakta fakat, deformasyon görülmemektedir. Buradaki sicaklık TMEB'den daha düşüktür ancak kaynak esnasında oluşan kararsız mikroyapılar kaynağın mekanik özelliklerini olumsuz yönde etkileyebilmektedir. Bu TMEB yoğun plastik deformasyon ve yüksek sicaklık yeniden kristalleşmeye sebep olmaktadır [22]. Kaynak öncesi ve sonrasındaki mikroyapılar Şekil 14'te gösterilmiştir.

Şekil 14. a) Ana metal bölgesinin kaynak öncesi mikroskoptaki 100x büyütmedeki görüntüsü, b) KB/TMEB bölgesinin kaynak sonrası mikroskoptaki 100x büyütmedeki görüntüsü

Y.C.Waterloo yaptığı çalışmada, farklı takım dönme hızları altında yapılan kaynaklar arasında kanca yüksekliği arasında bir fark olduğunu belirtmiştir. Ayrıca, takımın dönme hızı azaldığında, kanca yüksekliğinin arttığını, böylelikle üst ve alt levhalar arasındaki mekanik kilitlenmenin, daha yüksek bir 

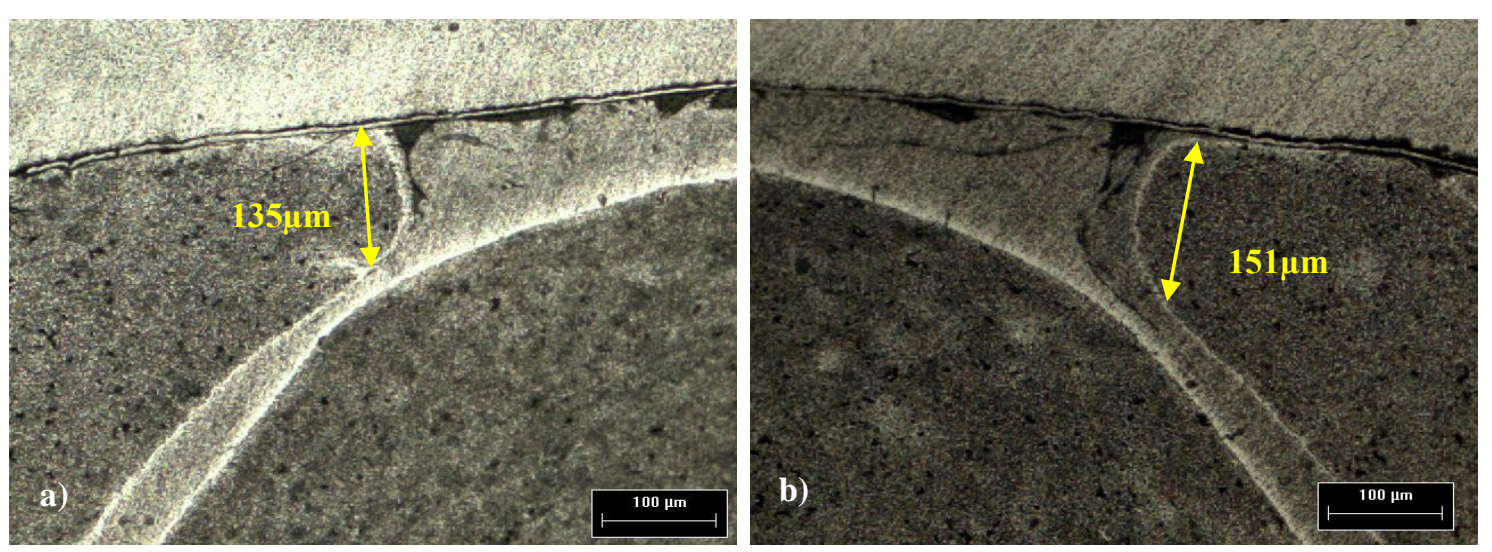

Şekil 15. Kanca bölgesinin 100x büyütmedeki görüntüsü, a) KB' nin solundaki (takım ilerleme yönünün tersi) ITAB bölgesinde kanca oluşumu, b) Sağ (takım ilerleme yönü) ITAB bölgesinde kanca oluşumu

Tane boyutu önemli bir mikroyapı parametresidir ki bu parametre çatlak büyümesini etkileyebilir. Özellikle korozif bir ortamda karışım bölgesindeki tane boyutu değişimi önemlidir. SKNK sırasında dinamik olarak yeniden kristalleşmenin karışım bölgesinde eş boyutlara sahip ince taneler meydana getirdiği kabul edilmektedir. SKNK parametreleri, takım geometrisi, iş parçasının bileşimi, iş parçasının sıcaklığı, basınç ve aktif soğumanın SKNK malzemelerinde yeniden kristalleşmiş tanelerin boyutuna önemli bir tesiri olmaktadir. AA2024-T3/Ni/AA2024-T3 malzeme çiftinin SKNK sonrası oluşan mikroyapı ve soğuma sırasında oluşan mikro çatlaklar Şekil 16'da gösterilmiştir [24].
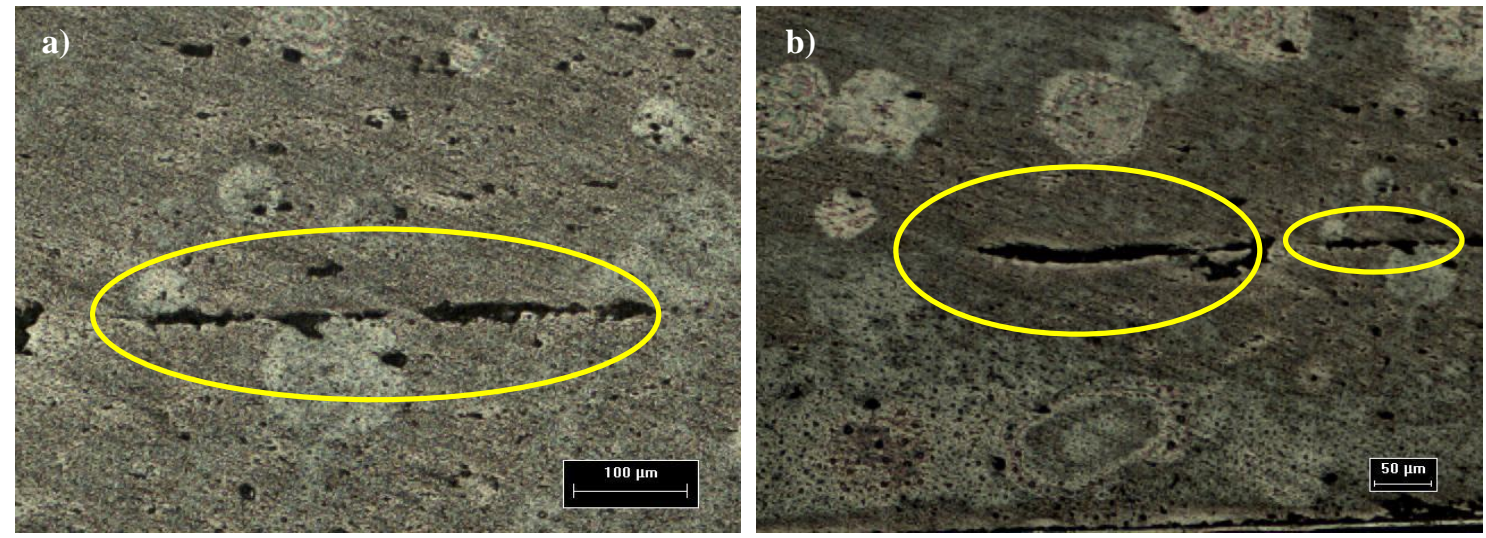

Şekil 16. a) Çatlak olan bölgenin mikroskoptaki 100x büyütmedeki görüntüsü, b) Birleşmeme hatası olan bölgenin mikroskoptaki 50x büyütmedeki görüntüsü

\subsection{Mikrosertlik Sonuçları}

Al alaşımları ana hatlarıyla, çökelme sertleşmesi alaşımları ve katı çözünme sertleşmesi, alaşımları içerisinde sınıflandırılırlar. SKK, genellikle çökelme sertleşmesi yapılmış $\mathrm{Al}$ alaşımlarındaki KB civarında yumuşatılmış bir bölge meydana getirir. Kaynağın ısıl dönüşümü esnasında, çökelme sertleşmesi ile tane büyümesi ya da çözünmesiyle böyle bir yumuşak bölgeye sebebiyet verir. Burada kaynaklanan metalin tokluğu da artmaktadır. Mustafa ve Mithat'ın yaptığ çalışmada ERNiCrMo3 ilave metali ile birleştirilen numunenin darbe tokluk değerleri test sıcaklığına bağ $l_{1}$ olarak nikelsiz yapılan kaynağın değerlerinden daha yüksek değerlere ulaştığı gözlemlenmiştir [25].

SKNK sonrası Al levhalara baktığımızda kaynak bölgesinde ölçülen değere göre kısmen bir yumuşama görülmüştür. ITAB ve TMEB bölgelerinde ise 60-65
HV değerlerinde sertlik ölçülmüştür. $\mathrm{Bu}$ değer, o bölgede sıcaklıktan dolayı tane boyutunun arttığını ve Al levhanın kısmen yumuşadığını göstermektedir. Nikel, alt ve üst Al levhanın sertlik değer grafiği Şekil 17 'de gösterilmiştir. Alt levhadaki sertliğin üst levhaya göre daha düşük olmasının nedeni, parçaların birleştirilmesi sırasında yüksek basınçtan kaynaklanan 1S1 girişi nedeniyle yumuşamasıdır. Kontrolsüz çökelme sonucu ikincil faz partiküllerinin irileşmesi ve tane sınırlarında kararlı fazlarının oluşması neticesinde, diğer numunelere nazaran önemli bir sertlik düşüşü meydana gelmiştir. Bu yumuşama mukavemet arttırıcı çökeltilerin çözülmesine ve/veya kabalaşmasına neden olmaktadır [26]. Kaynak arayüzeyinde oluşan $\mathrm{Ni}_{3} \mathrm{Al}$ matris alaşımının tane boyutundan çok daha küçük tane boyutuna sahip bir dinamik yeniden kristalleşme bölgesi oluşmuş olup sertlik artışı meydana gelmiştir [21]. 


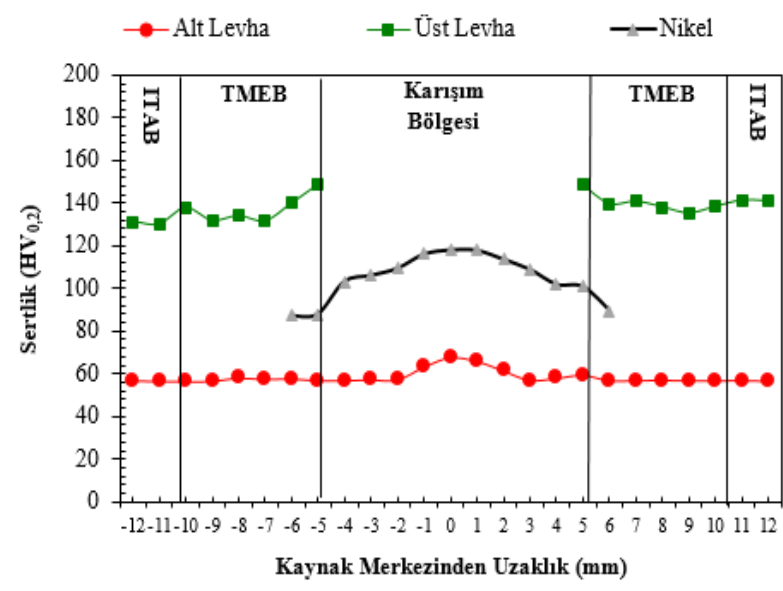

Şekil 17. SKNK sonrası Al levhaların Ni kaplama bölgesi ile alt ve üst bölgelerinin mikrosertlik grafiği

\section{GENEL SONUÇLAR}

Bu çalışmada, Ni kaplı ve kaplanmamış AA-2024-T3 alaşımlı levhalar SKNK yöntemiyle birleştirilmiştir. Maksimum ve minimum çekme makaslama kuvvetleri belirlenmiştir. Sonuçlar aşağıda özetlenmiştir.

1. Ni kaplanmış alüminyum ve kaplanmamış alüminyum levhaların SKNK işlemi başarılı olarak gerçekleştirilmiştir.

2. Çalışmadan elde edilen verilere göre, $\mathrm{Ni}$, metalinin alüminyum metalin kaynaklanabilirliği üzerinde çekme-makaslama kuvvetini arttırıcı özellikler gösterdiği bulunmuştur.

3. Numunelerin çekme-makaslama kuvveti ve \% uzama değerleri belirlenmiştir. Ara malzeme ilavesiz birleştirilen numunenin ortalama çekmemakaslama kuvveti $6,78 \mathrm{kN}$ ve $\%$ uzama değeri $\%$ 3,56 olarak görülmüştür. Ni kaplı birleştirmenin ortalama çekme-makaslama kuvveti $7,91 \mathrm{kN}$ ve uzama değeri \%3,23 olarak belirlenmiştir.

4. Çekme makaslama kuvvetlerine bakıldığında Ni alaşımının alüminyum alaşımının kaynaklanabilirliği üzerinde olumlu etki yarattığ görülmüştür.

5. Karıştırıcı uç uzunluğu ve profillleri kaynak dayanımını doğrudan etkiye sahip olup, kanca dayanımını arttırarak çekme makaslama testinde olumlu sonuçlar vermiştir.

6. SKNK sonrası Al levhalar, KB'de ölçülen değere göre kısmen bir yumuşama görülmüştür. ITAB ve TMEB bölgelerinde ise 60-65 HV değerlerinde sertlik elde edilmiştir. Bu değer, o bölgelerdeki sicaklıktan dolayı tane boyutunun arttığı ve $\mathrm{Al}$ levhanın kısmen yumuşadığından dolayıdır.

7. Kanca boylarının $135 \mu \mathrm{m}$ ve $151 \mu \mathrm{m}$ olduğu belirlenmiştir. Bu durum ana metal ve kaplanmış metalin difüzyonunu arttırmış olup mekanik özelliklerini olumlu yönde etkilemiştir.

\section{Teşekkür (Acknowledgment)}

FEN-C-YLP-100719-0245 numaralı proje kapsamında verdiği finansal destekten ötürü Marmara Üniversitesi
Bilimsel Araştırma Projeleri Birimine (BAPKO) sonsuz şükranlarımızı sunarız.

\section{REFERANSLAR}

[1] Coşkun M. H. (2009). Otomotiv endüstrisinde kullanılan IF 7114 ve DP 600 çelik sacların direnç nokta kaynağı ve sürtünme karıştırma nokta kaynağı yöntemleri ile birleştirilmesi. Yüksek Lisans Tezi, Kocaeli Üniversitesi Fen Bilimleri Enstitüsü, Türkiye.

[2] Kurt, A. (1990). Katı hal kaynak teknikleri. Gazi Üniversitesi Fen Bilimleri Enstitüsü, Yüksek Lisans Ders Notları, Ankara, 1-10.

[3] Bilici, M. K., Bakır, B., Bozkurt, Y., Çalış, İ. (2016). Taguchi analysis of dissimilar aluminum sheets joined by friction stir spot welding. Pamukkale Üniversitesi Müh. Bilim Dergisi. 22(1), 17-23.

[4] Matsuyama, K. (2006). Trends of automobile vehicles and the joining technologies. International Institute of Welding Document, IIW Doc. III- 1386-06,

[5] Yamamoto, M., Gerlich, A., North, T.H., Shinozaki, K. (2007). Mechanism of cracking in AZ91 friction stir spot welds. Science and Technology of Welding and Joining, 12, 208-216.

[6] Thornton, P., Krause, A., Davies, R. (1996). "Aluminium spot weld", Welding Journal, 75, 101-108.

[7] Spinella, D.J., Brockenbrough, J.R., Fridy, J.M. (2005). Trends in aluminium resistance spot welding for auto industry. Welding Journal, 84, 35-40.

[8] Oruç, E., Kalender, M., Ulupınar, H., Bozkurt, Y. (2019). Sürtünme karıştırma nokta kaynağı ile birleştirilen ara katmanlı AA2024-T3 levhaların mikroyapı ve mekanik özelliklerinin incelenmesi. Uluslararası Fen Matematik ve Mühendislik Bilimleri Kongresi, İzmir, Türkiye.

[9] Meran, C., Çolak, M. (2008). Tool holder design for friction stir welding. Gazi Üniversitesi Mühendislik ve Mimarlık Fakültesi Dergisi, 23(3): 671-679.

[10] Kalender, M., Kılıç, S.E., Bozkurt, Y., Salman, S., Turker, A. (2009). Design and development of portable fixture for various dimensions specimens joining by friction stir welding. Orta Doğu Uluslararası Multidisipliner Çalışmalar Konferans1.

[11] Kalender, M., Kılıç, S.E., Bozkurt, Y., Ersoy, S., Salman, S. (2018). Farklı malzemelerin sürtünme karıştırma kaynağında takım geometrisinin mekanik özelliklere etkisi. International Conference on Welding Technologies and Exhibition, Saraybosna, Bosna Hersek.

[12] Kahraman, B. (2009). Otomotiv endüstrisinde kullanılan 5754 alüminyum alaşımı sacların direnç nokta kaynağı ve sürtünme karıştırma nokta kaynağı yöntemleri ile birleştirilmesi. 
Yüksek Lisans Tezi, Kocaeli Üniversitesi Fen Bilimleri Enstitüsü, Kocaeli.

[13] Khan, N. Z., Siddiquee, A. N., Khan, Z. A. (2017). Friction stir welding dissimilar aluminum alloys, CRC Press Taylor \& Francis Group.

[14] Badarinarayan, H., Hunt, F., Okamoto, K. (2007). Friction stir welding and processing. American Society for Metals, 235-250, America.

[15] Bozkurt, Y. (2008). Sürtünme karıştırma kaynak tekniği ile birleştirilen AA2124/SiCp/25 kompozit levhaların mekanik özellikleri ve mikroyap1 karakterizasyonu. Doktora Tezi, Marmara Üniversitesi Metal Eğitimi Bölümü, İstanbul.

[16] Dawes, C.J. (1999). Friction stir welding. The Welding Institute, TALAT Lecture 4410 Cambridge, 1-13.

[17] Dawes, C.J., Thomas, W.M. (1996). Friction stir process welds aluminum alloys. Welding Journal, 75 (3),41-45.

[18] Soytemiz, G. (2019). Cu ve Ni Kaplanmış Alüminyum Alaşımlı Levhaların Sürtünme Karıştırma Nokta Kaynağı. Yüksek Lisans Tezi, Marmara Üniversitesi Metalurji ve Malzeme Mühendisliği Programı, İstanbul.

[19] Bozkurt, Y., Salman, S., Turker, A. (2018). The investigation and comparison of friction stir spot welding and electrical resistance spot welding of AA2024 aluminum alloy joints. ICENS 4th International Conference on Engineering and Natural Science, Kiev, Ukraine.

[20] Kaçar, R., Emre, H., Demir, H., Gündüz, S. (2011). Al-Cu-Al malzeme çiftinin sürtünme karıştırma nokta kaynak kabiliyeti. J. Fac. Eng. Arch. Gazi Univ., Vol 26, No 2, 349-357.

[21] Arıcı, G. (2013). Nikel alüminatların sürtünme kaynağı ile birleştirilebilirliklerinin araştırılması. Yüksek lisans tezi, Metalurji Mühendisliği Anabilim Dalı, Ocak.

[22] Chung-Wei, Y., Fei-Yi, H., Truan-Sheng, Lui., Li-Hui, C., Jiun-Yu, J. (2009). Weibull statistics for evaluating failure behaviors and joining reliability of friction stir spot welded 5052 aluminum alloy. Materials Transactions, Vol. 50, No. 1, 145-151.

[23] Yuyang Chen, W. (2015). Refill friction stir spot welding of dissimilar alloys", Ontario, Canada, pp.18.

[24] Yan, J. (2004). Fundamental study in fsw processing and fsw process-structure property relationship for AA2024 and AA2524. PhD Thesis, Department of Mechanical Engineering and Information Technology, University of South Carolina.

[25] Tümer, M., Kerimak, M.Z.. (2017) Nikel bazlı süper alaşım inconel 625 ile AISI 304L paslanmaz çelik malzeme çiftinin birleştirilmesinde farklı ilave metallerin tokluk ve mikroyapısal özelliklere etkisi, El-Cezerî Fen ve Mühendislik Dergisi Cilt: 4, No: 1, 116-126.

[26] Bozkurt, Y., Salman, S., Cam, G. (2013). Effect of welding parameters on lap shear tensile properties of dissimilar friction stir spot welded AA 5754-H22/2024-T3 joints. Science and Technology of Welding and Joining, Vol 18, No 4, pp. 337-345. 